\title{
Chapter 14 \\ Archive of Historical Earthquake Data for the European-Mediterranean Area
}

\author{
Andrea Rovida and Mario Locati
}

\begin{abstract}
The importance of historical earthquake data is largely recognized by both seismologists and engineers, who use such data in a wide range of applications.

At the European-Mediterranean scale, several databases dealing with historical earthquake data - mostly intensity data points - exist and are constantly maintained and updated, as well as national earthquake catalogues. In addition, a number of studies on historical earthquakes are published every year. Most of these activities are being performed at a national scale, depending on each country's needs, and according to diverse methodologies. As a result, the earthquake history of Europe is today fragmented in a puzzle of different, only partially overlapping sets of data, which, at the continent scale, are not homogeneously collected and interpreted. This situation is particularly evident in the frontier areas, where historical earthquakes are often interpreted in a conflicting and/or partial way by the catalogues of the bordering countries. In addition, the background information upon which several historical catalogues are built is not published or not easily accessible.
\end{abstract}

In recent years, a major effort was made to bridge over these gaps, by establishing cooperation among existing national databases, and creating new ones according to common standards. Particular attention was devoted to retrieve the earthquake background information, that is, the results of historical earthquake investigation in terms of a paper, a report, a book chapter, a map, etc. As most of the information on an historical earthquake can be summarized in a set of Macroseismic Data Points (MDPs) - i.e. a list of localities (name and coordinates) with a macroseismic intensity assessment and the related macroseismic scale - a dedicated effort was addressed to make such data publicly available.

The described activities resulted in the European Archive of Historical Earthquake Data (AHEAD). The Archive is conceived as a pan-European common and open platform supporting the research activities in the field of historical seismology by (i) tracing back, preserving and granting access to the sources of data on the earthquake history of Europe (papers, reports, MDPs, and catalogues), and (ii) establishing relations among these data. AHEAD inventories multiple sets of information concerning each European earthquake in the time-window 1000-1899.

\footnotetext{
A. Rovida $(\bowtie) \cdot$ M. Locati

Istituto Nazionale di Geofisica e Vulcanologia, Milano, Italy

e-mail: andrea.rovida@ingv.it; mario.locati@ingv.it
} 
The AHEAD web portal (http://www.emidius.eu/AHEAD/) gives access, as of today, to 4,722 earthquakes and the related background information as provided by 338 data sources. All these data can be queried by earthquake and by study, through a user-friendly web-interface. The distinguishing feature of AHEAD is to grant access not only to one study, but to all the available (published) data sources dealing with each individual earthquake, allowing researchers to take into account the different point of views and interpretations.

\subsection{Introduction}

The importance of historical earthquake data is broadly recognized by both seismologists and engineers, who use such data in a wide range of applications, including seismotectonic studies, seismic hazard assessments for supporting building codes and critical facilities, and land use planning.

Earthquake catalogues represent the most popular and ready-to-use type of historical earthquake data, since they provide a list of earthquakes complemented with the same parametric information (epicentral coordinates, hypocentral depth, magnitude, etc.) as instrumental earthquake catalogues. They constitute one of the basic ingredients for the mentioned applications, and represent the final result and summary of historical earthquake research.

Over the past decades the compilation of earthquake catalogues in Europe, as well as historical earthquake research, has been performed at national scales, depending on each country's needs, and according to diverse methodologies. Each European country put major efforts in compiling an historical earthquake catalogue for its own territory according to its own procedures; such catalogues are still today maintained and updated according to different time-schedule and criteria. Several databases dealing with historical earthquake data - mostly intensity data points - have also been published in Europe. In addition, a number of studies on historical earthquakes, either on single events or specific historical periods and areas, are published every year in the scientific literature.

As a result, the earthquake history of the European-Mediterranean area is fragmented in a puzzle of different, only partially overlapping sets of data, which, at the continent scale, are not homogeneously collected and interpreted.

In recent years a major effort, started in 2006 in the framework of the European Commission project NERIES ("Network of Research Infrastructures for European Seismology"), was made to establish cooperation among existing national databases, and creating new ones according to common compilation standards. Such an effort resulted in the Archive of Historical Earthquake Data (AHEAD). The Archive is conceived as a pan-European common and open platform supporting the research activities in the field of historical seismology by (i) tracing back, preserving and granting access to the sources of data on the earthquake history of Europe (papers, reports, MDPs, and catalogues), and 
(ii) establishing relations among these data. AHEAD covers the time-window 1000-1899 and is available through a dedicated web-portal since May 2010 at http://www.emidius.eu/AHEAD/. The AHEAD portal inventories and gives access to multiple sets of information concerning each earthquake, and allows users to get comprehensive information about individual earthquakes.

\subsection{Content of the Archive}

Primary historical earthquake data are written records of seismic effects, as supplied by historical sources. These primary data are then put together and interpreted in historical earthquake studies, aimed at retrieving a comprehensive description of the earthquake impact, from which the earthquake location and size can be evaluated for the compilation of parametric catalogues. Catalogues usually mention the data supporting each earthquake, being them historical sources, one or more historical earthquake studies, or another parametric catalogue. Historical earthquake data present themselves in a variety of different formats. Some studies simply consist in the transcription of the historical sources, with or without any interpretation of them. On the contrary, other studies just present the interpretation of historical sources, making reference to them or even, in extreme cases, not. Modern in-depth historical studies should provide a comprehensive description of the historical sources, the historical context in which these sources were produced, how and where they were preserved, and how they were retrieved; historical sources should then be critically analysed and interpreted in terms of earthquake effects. The effects distribution is either provided as a mere description or, in modern studies, interpreted in terms of Macroseismic Data Points (MDPs), i.e. a list of places with name and coordinates with a macroseismic intensity assessment and the related macroseismic scale, as a minimum. In some cases the complete earthquake study is not formalized and only MDPs are provided. Although inhomogeneous at the European scale, the results of the mentioned studies and investigations (hereafter referred to as "data sources"), involving and gathering different disciplines and expertise, provide scientific results that altogether constitute the knowledge on a given historical earthquake.

One of the main scopes of AHEAD is tracing back, preserving and granting access to the data sources on historical earthquakes in Europe. The compilation of AHEAD started from the identification, collection and critical organization of the best and most recent data sources in any of the formats briefly analysed above. Following the identification of the data sources dealing with a given earthquake, the full information on such earthquake has been extracted from the data source and a record of the AHEAD database has been compiled. The AHEAD database structure is described in Locati et al. (2014). As an earthquake can be the subject of multiple studies, multiple records from different data sources can relate to the same earthquake. Conversely, one data source may deal with several earthquakes and contribute several records to AHEAD. Records referred to the same earthquake have 


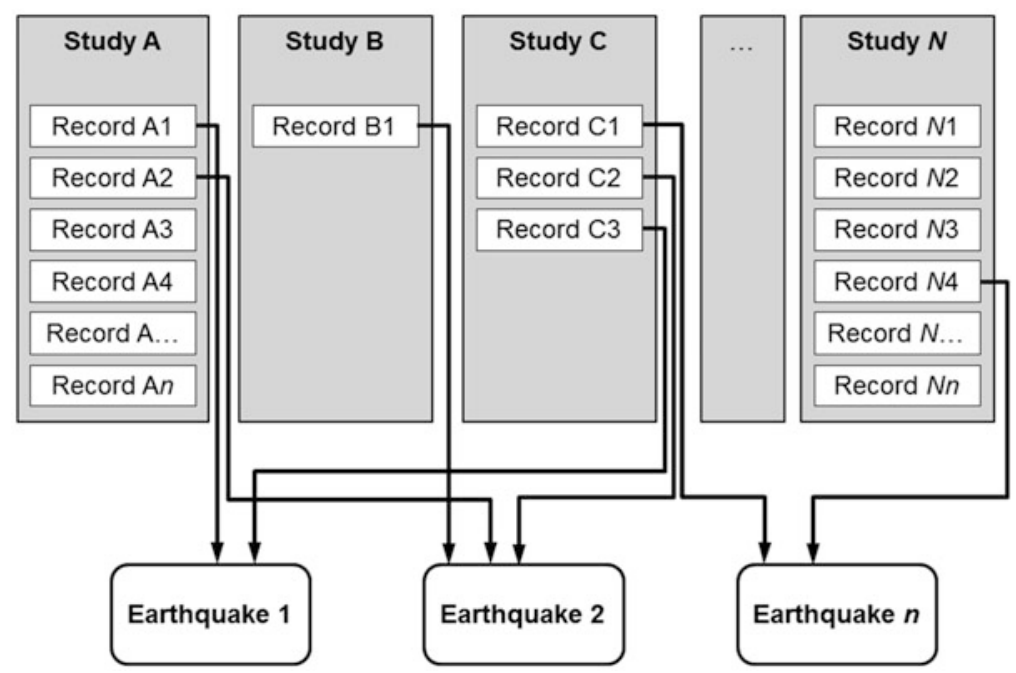

Fig. 14.1 Scheme of the compilation of AHEAD

been then grouped together by means of the same identification number (see Locati et al. 2014). As a result each earthquake is represented in AHEAD by the multiplicity of the data sources related to it, as shown in Fig. 14.1. In this way, the information supporting each earthquake is easily traced back and the state-of-theart of the research on a specific earthquake is fully represented.

Different data sources may provide conflicting information and grouping records referred to the same earthquake is not always easy, for example if the same earthquake is reported in different studies with different dates (a common situation for historical earthquakes in Europe, where different calendars have been in use through history). For this reason, the grouping of records was manually performed, case by case by expert judgment, examining and comparing the content of each study. Automatic clustering has been avoided, since it may lead to big mistakes when data sources provide for the same earthquake different time and location.

AHEAD today considers 4,722 earthquakes in the Euro-Mediterranean area in the time window 1000-1899 (Fig. 14.2), as described in 338 data sources; the total number of records of the AHEAD database is 11,018 .

Two thirds of AHEAD data are contributed by eight regional online databases, run by European institutions involved in historical earthquake research: ASMI (ASMI Working Group), ECOS-09 (Fäh et al. 2011), SisFrance (BRGM-EDFIRSN/SisFrance 2010), Macroseismic Data of Southern Balkan area (University of Thessaloniki 2003), Base de Datos Macrosísmica (Instituto Geografíco Nacional 2010), UK Historical Earthquake Database (British Geological Survey 2010), Hellenic Macroseismic Database (Kouskouna and Sakkas 2013) and Base de Dades Macrosísmica (Institut Geològic de Catalunya 2010). The remaining one third of the data sources inventoried by AHEAD is constituted by (i) papers, reports, and volumes describing the results of historical earthquake investigations, and 


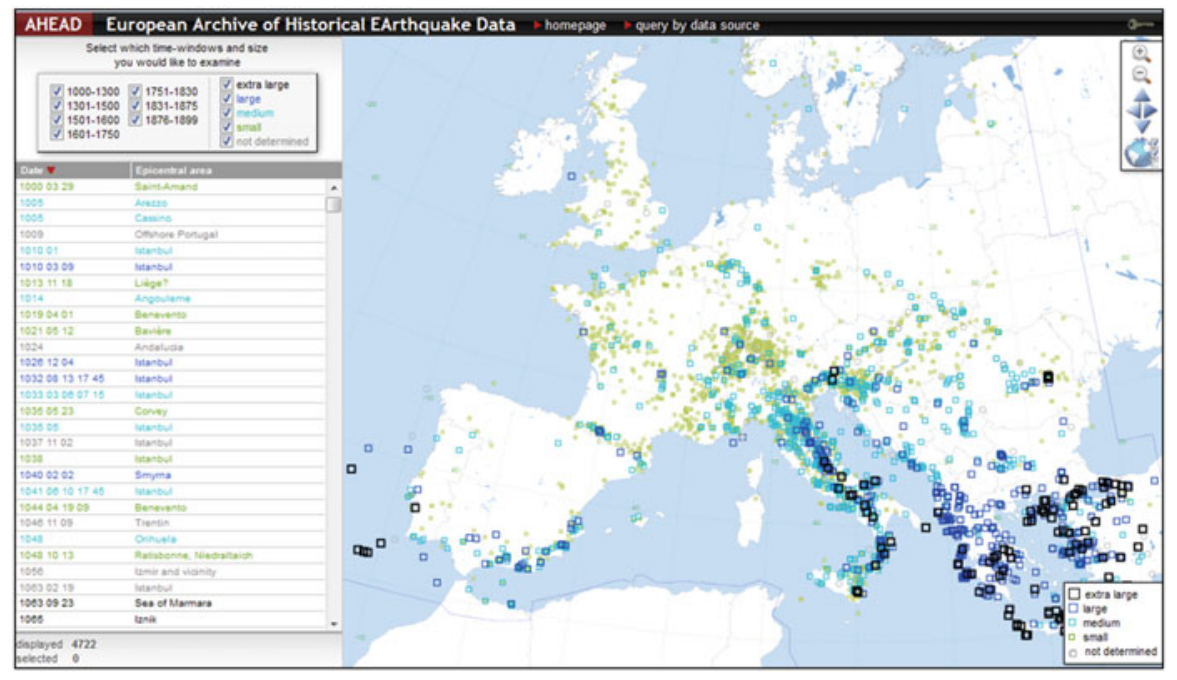

Fig. 14.2 Plot of the 4,722 earthquakes (1000-1899) considered by AHEAD, from the "query by earthquake" section of the AHEAD portal

(ii) parametric catalogues, with or without the references to their sources of information.

In the AHEAD portal each data source is listed in the "Query by data source" section, which give access to the data source full reference, the complete text as a PDF file, if possible, and the link to online data sources (e.g., databases and catalogues) when available. The archive can be queried also by earthquake (Fig. 14.2); once an earthquake is selected either from a list or a map, the user may investigate the available information, subdivided into two sections: (i) "Catalogues", supplying the parameters extracted from the main catalogues, and (ii) "Studies", showing the list of the relevant earthquake investigations. When available, the MDP set from each study is shown in a map.

\subsection{Use and Potential of AHEAD}

All earthquake catalogues and intensity databases provide one set of data per earthquake. AHEAD conversely grants access to multiple data sources per earthquake, each supplying different kinds of data, such as MDPs sets and earthquake parameters.

The number of data sources made available for each of the 4,722 considered earthquakes ranges from 1 to 10; at least two alternative data sources are archived for the $77 \%$ of the earthquakes, and for the $14 \%$ of them at least four data sources are available. Alternative data sources may supply different interpretations of the same earthquake, resulting in alternative data. Figure 14.3 shows the availability of 

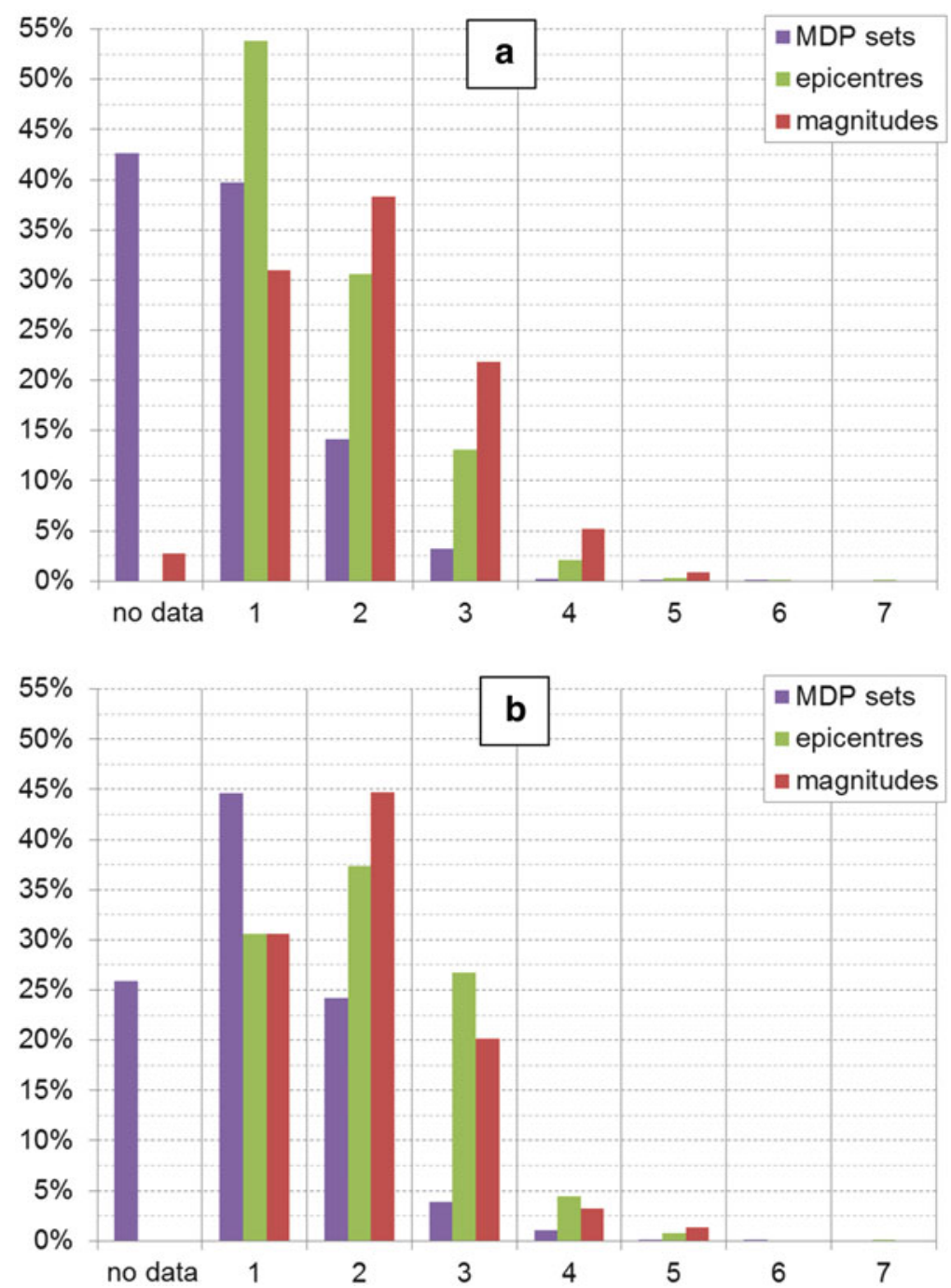

Fig. 14.3 Number of alternatives per earthquake: (a) percentages for all 4,722 earthquakes, (b) percentages only for earthquakes with $\mathrm{Mw} \geq 5.6$

alternative solutions in terms of (i) alternative MDP sets; (ii) alternative epicentres, and (iii) alternative magnitude assessments; Fig. 14.3a refers to all the 4,722 considered earthquakes, Fig. 14.3b refers to the most damaging earthquakes (indicatively $\mathrm{M} \geq 5.6$ ).

In the compilation of AHEAD, particular attention was devoted to retrieve data sources providing Macroseismic Data Points (MDPs), since they supply a comprehensive and quantitative image of an earthquake. As a whole, about 5,000 MDPs sets derived from 147 different data sources are archived, for a total of more than 
94,500 MDPs. For the $57 \%$ of the 4,722 considered earthquakes, AHEAD archived at least one MDP set; considering the 818 earthquakes with $\mathrm{M} \geq 5.6$, MDPs are available for the $74 \%$ of them. For the $39 \%$ of the archived earthquakes only one MDP set is available, while alternative sets exist for the $18 \%$ them, about the $15 \%$ is represented by earthquake with two alternative sets (Fig. 14.3a). For earthquakes with $\mathrm{M} \geq 5.6$, the percentages of $\mathrm{M} \geq 5.6$ earthquakes with one, two, or more MDP sets are 45, 24, and $5 \%$ respectively (Fig $14.3 \mathrm{~b}$ ). Figure 14.3 also shows the same analysis on alternative epicentres and magnitude values.

AHEAD provides the full representation of the wealth of alternative solutions for each European historical earthquake, granting access to the available knowledge of it and, at the same time, to the uncertainty associated to the interpretation of past earthquakes.

The exploration of alternative solutions is particularly important for the evaluation of earthquakes in frontier areas, where historical earthquakes are often interpreted in a conflicting and/or partial way by the catalogues of the bordering countries. Differences depend, among other factors, on the considered historical sources, and the way they were interpreted by each author. Figure 14.4 shows the diversity of data sources available for the 14 April 1895, Ljubljana earthquake, as represented in the AHEAD portal. The 1895 earthquake is a transfrontier event that affected a large area today split among three bordering countries (Slovenia, Austria, and Italy). Although the available parametric catalogues propose similar epicentral locations and magnitude values around 6 (Fig. 14.4a), the two alternative MDP distributions by Guidoboni et al. (2007) and Cecić (1998), respectively shown in Fig. 14.4b,c, lead to a very different earthquake scenario. AHEAD, providing access to these different scenarios and an easy comparison of different datasources on the same earthquake, stimulated a complete reappraisal of the earthquake (Cecić et al. 2014).

The described situation is common for European cross-border earthquakes, for which MDPs distributions are often limited to one country and the effects in the bordering country have not been investigated. Alternatively, a second MDPs distribution is available for the neighbouring country and is referred to another, supposed local earthquake. Such partial effects distributions reflect on the final location and size of the earthquake, which may either be located in the country where the effects have been recognized or listed in the catalogues of both the bordering countries, each with its own (wrong) location and magnitude. AHEAD lists all the available data sources for the same earthquake and helps sorting out the described situations.

The value of AHEAD is not only limited to emphasize different interpretations by different authors, but also to keep trace of the evolution of the knowledge of an earthquake, as the historical investigation progresses, the understanding of the phenomena grows. The more complete is the overall picture, the more is possible to assess the confidence level of the earthquake parameters proposed by a catalogue.

AHEAD provided the list of earthquakes for the compilation of the European earthquake catalogue SHEEC (SHARE European Earthquake Catalogue; Stucchi 


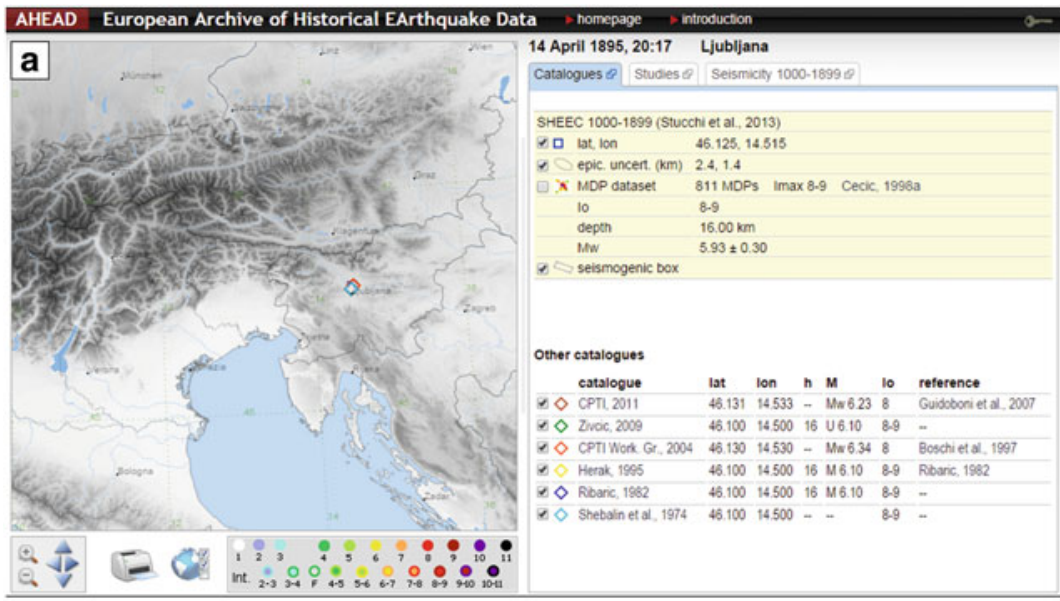

AHEAD European Archive of Historical EArthquake Data

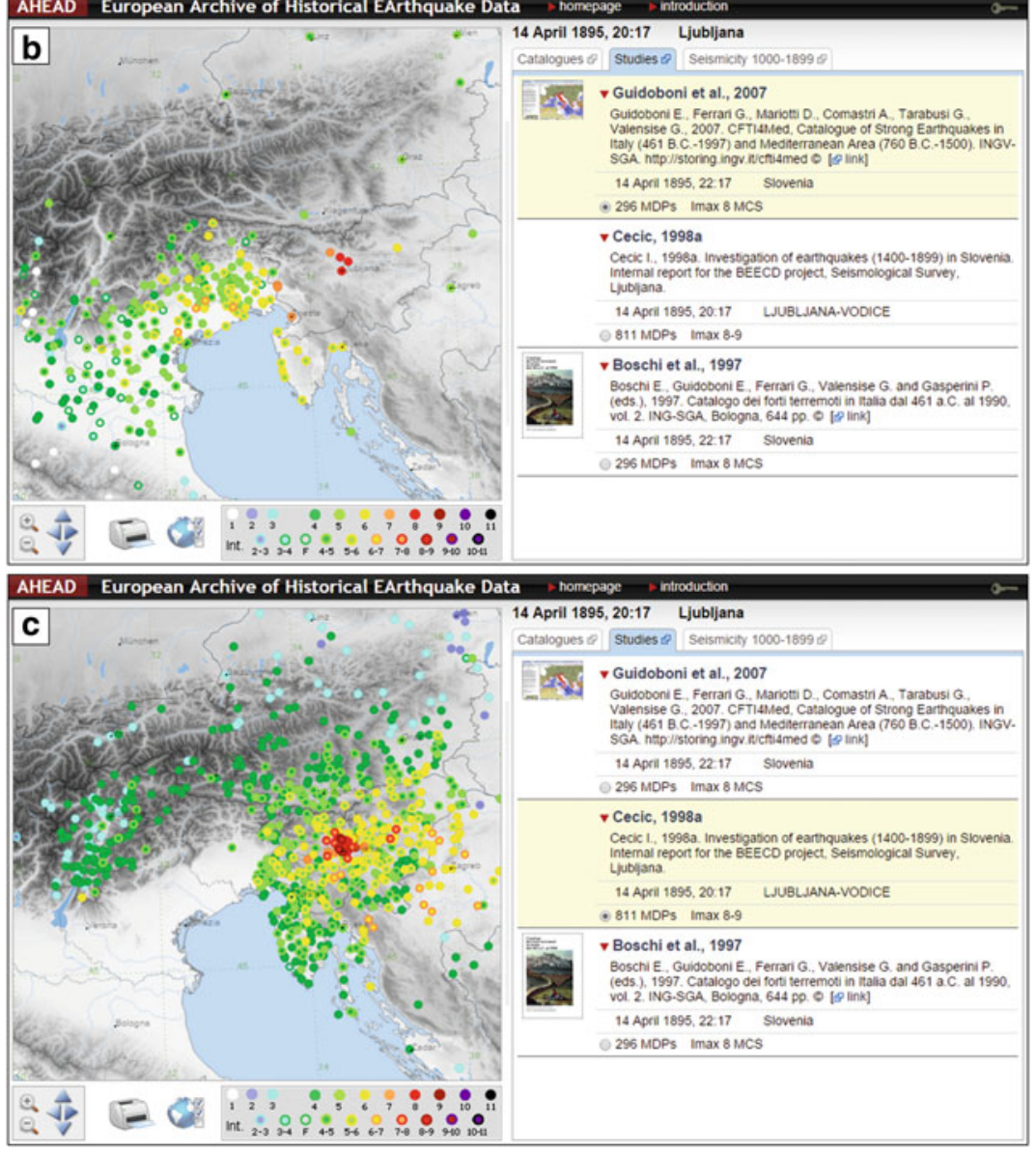

Fig. 14.4 The 14 April 1895, Ljiubljana earthquake: (a) parameters according to different catalogues, (b) the MDP set as provided by Guidoboni et al. (2007), and (c) as provided by Cecić (1998) 
et al. 2012) 1000-1899, used for the evaluation of the seismic hazard of Europe in the framework of the SHARE (Seismic Hazard Harmonization in Europe) EC Project (Giardini et al. 2014). AHEAD permitted a careful comparison of the available data sources for each earthquake and the selection, among them, of the most reliable, upon which the catalogue entry have been built. AHEAD also permitted to critically deal with the situations described above, in particular to sort out: (i) duplications, (ii) earthquakes missing in one or more catalogues, and (iii) fake events. In particular, AHEAD allowed the compilers of SHEEC to identify 306 earthquakes not mentioned in national catalogues, commonly because investigated for the first time by studies published after the national catalogues.

\subsection{Long-Term Plan}

AHEAD is proposed as the reference node for providing historical data on European earthquakes for EPOS, the European Plate Observing System (Cocco and the EPOS Consortium 2013). EPOS is a long-term integrated research infrastructure plan of the European Commission aimed at integrating data from existing national and regional research infrastructures in order to increase the accessibility and usability of multidisciplinary data, enhancing worldwide interoperability in Earth science. AHEAD is the "Community Layer" that will interface national and regional research infrastructures with the cross-domain "Integrated Services" of EPOS, allowing researchers from different fields to access historical earthquake data.

The long-term plan of AHEAD foresees its expansion both in time and space, a new section in the portal for fake earthquakes, the promotion of common standards for the compilation of historical earthquake data, and a support for dedicated research activities on cross-border earthquakes. The covered time-window will be extended to the first half of the 20th century, this will lead to an exponential increase of the number of earthquakes and an additional complexity in order to accommodate (early) instrumental earthquake data together with the existing macroseismic ones. The extension in space will start with the integration of Central and Eastern Turkey; the extension to other Mediterranean areas is envisioned in the long term. A section dealing with fake earthquakes will be opened in the portal. During its compilation, AHEAD dedicated particular care in archiving studies that identify earthquakes as fake, for example other natural phenomena that have been wrongly interpreted as earthquakes and included in earthquake catalogues. AHEAD deals with about 350 fake earthquakes and it will help avoiding the inclusion of such earthquakes in future catalogues. The structure of AHEAD will permit to clearly understand why an event is declared as a fake by tracing back the misinterpretation of the historical sources.

AHEAD will continue promoting common compilation standards among the involved research infrastructures. The next milestone in this field will be the finalization of a shared file format for exchanging macroseismic data (Locati 
2014), based on the extension of the existing QuakeML format (Schorlemmer et al. 2006), already in use for exchanging event parameters originated from instrumentally recorded data.

Finally, AHEAD will support new research initiatives aimed at investigating cross-border earthquakes which today present conflicting or partial data in different regional databases, and for those earthquakes with a complete lack of background information.

\subsection{Conclusions}

AHEAD provides a consistent description of the Euro-Mediterranean long-term earthquake history, allowing researchers to better exploit historical earthquake data spanning over a millennium.

AHEAD helps users to easily retrieve and compare the largest amount of available, historical earthquake data and to better understand the origin of different interpretations. This goal is achieved by (i) tracing back, preserving, and granting access to the studies and the parameters for each earthquake and (ii) creating relations among these studies. AHEAD is available on the web with a user interface designed to emphasize its distinctive features.

The cooperation of more than 50 researchers from more than 20 European research institutions and countries, supported by two European initiatives (2006-2013), contributed to the creation and establishing of AHEAD. Now that a consistent description of the Euro-Mediterranean long-term earthquake history does exist, through the increased awareness and cooperative action of the European and national research institutions, AHEAD could become a durable platform continuously fed with new pieces of information on past earthquakes.

Open Access This chapter is distributed under the terms of the Creative Commons Attribution Noncommercial License, which permits any noncommercial use, distribution, and reproduction in any medium, provided the original author(s) and source are credited.

\section{References}

ASMI Working Group ASMI, Archivio Storico Macrosismico Italiano. http://emidius.mi.ingv.it/ ASMI/

BRGM-EDF-IRSN/SisFrance (2010) Histoire et caractéristiques des séismes ressentis en France. http://www.sisfrance.net/

British Geological Survey (2010) UK historical earthquake database. http:/quakes.bgs.ac.uk/ historical/

Cecić I (1998) Investigation of earthquakes (1400-1899) in Slovenia. Internal report for the BEECD project, Seismological Survey, Ljubljana 
Cecić I, Albini P, Hammerl CH (2014) 14 April 1895, Ljubljana earthquake - a cross-border study. Abstract volume of the 2nd European conference on earthquake engineering and seismology, Istanbul, 25-29 Aug 2014

Cocco M, EPOS Consortium (2013) The EPOS architecture: integrated services for solid earth science. Geophys Res Abstr 15:EGU2013-5531

Fäh D, Giardini D, Kästli P, Deichmann N, Gisler M, Schwarz-Zanetti G, Alvarez-Rubio S, Sellami S, Edwards B, Allmann B, Bethmann F, Wössner J, Gassner-Stamm G, Fritsche S, Eberhard D (2011) ECOS-09 earthquake catalogue of Switzerland release 2011 report and database, public catalogue. Swiss Seismological Service ETH, Zurich, Report SED/RISK/R/ 001/20110417, 42 pp. + Appendices; http://hitseddb.ethz.ch:8080/ecos09

Giardini D, Wössner J, Danciu L (2014) Mapping Europe's seismic hazard. Eos 95(29):261-262

Guidoboni E, Ferrari G, Mariotti D, Comastri A, Tarabusi G, Valensise G (2007) CFTI4Med, catalogue of strong earthquakes in Italy (461 B.C.-1997) and Mediterranean Area (760 B.C.1500). INGV-SGA. http://storing.ingv.it/cfti4med

Institut Geològic de Catalunya (2010) Base de Dades Macrosísmica. http://www.igc.cat/web/ca/ sismologia_bdmacrosis.html

Instituto Geografíco Nacional (2010) Bases de datos macrosísmica. http://www.ign.es/ign/ layoutIn/bdmacrosismica.do

Kouskouna V, Sakkas G (2013) The University of Athens Hellenic Macroseismic Database (HMDB.UoA): historical earthquakes. J Seismol 17(4):1253-1280. http://macroseismology. geol.uoa.gr/

Locati M (2014) Describing non-instrumental seismological data in Quakeml: the need for a macroseismic extension. Abstract volume of the 2nd European conference on earthquake engineering and seismology, Istanbul, 25-29 Aug 2014

Locati M, Rovida A, Albini P, Stucchi M (2014) The AHEAD portal: a gateway to European historical earthquake data. Seismol Res Lett 85(3):727-734

Schorlemmer D, Saul J, Euchner F, Becker J, Heinloo A, Kästli P, Maraini S, Weber B, Wyss A (2006) QuakeML, an XML representation of seismological data, part 1: basic event description. Deliverable of the Joint Research Activity 2, NERIES Project, $35 \mathrm{pp}$

Stucchi M, Rovida A, Gomez Capera AA, Alexandre P, Camelbeeck T, Demircioglu MB, Gasperini P, Kouskouna V, Musson RMW, Radulian M, Sesetyan K, Vilanova S, Baumont D, Faeh D, Lenhardt W, Makropoulos K, Martinez Solares JM, Scotti O, Zivcic M, Albini P, Batllo J, Papaioannou C, Tatevossian R, Locati M, Meletti C, Viganò D, Giardini D (2012) The SHARE European earthquake catalogue (SHEEC) 1000-1899. J Seismol 17:523-524

University of Thessaloniki (2003) Macroseismic data of Southern Balkan area. http://www.itsak. gr/en/db/data/macroseismic_data/ 